\title{
Aporofobia, segregación y descenso a los infiernos
}

\author{
Parasite | Bong Joon Ho | 2019
}

\section{Francisca Ramón Fernández"}

\author{
Universitat Politècnica de València (España)
}

Josep Prósper Ribes

Universitat Politècnica de València (España)

Recibido 23 de abril 2020; aprobado 22 de septiembre 2020

\begin{abstract}
Resumen
El rechazo al pobre y la segregación aparecen de forma muy evidente en el film coreano Parásitos. En el presente trabajo se analiza esta película que representa un ejemplo de los problemas sociales de las clases más desfavorecidas, relacionando los aspectos narrativos con los jurídicos, mostrando a lo largo del relato la distinta situación social que tienen los personajes dependiendo de su trabajo y de su riqueza. Las clases sociales más desfavorecidas emanan un olor que no se puede eliminar con la limpieza y que provoca el rechazo de las clases sociales acomodadas. La separación de clases sociales se manifiesta a través de espacios arquitectónicos, planos cinematográficos y detalles, donde siempre el rico está en lo más alto, y el pobre, en lo más bajo. El cine se convierte en un portavoz de aspectos sociales y jurídicos y nos muestra una sociedad enferma y degradada, hasta sus últimas consecuencias.
\end{abstract}

Palabras Clave: Parásitos | aporofobia | segregación | derechos humanos

Aporophobia, segregation and descent into hell

\begin{abstract}
Rejection of the poor and segregation appear very clearly in Korean film Parasite. In this paper this film is analyzed, which represents a clear example of the social problems of the most disadvantaged classes, relating the narrative aspects to the legal ones, showing throughout the story the different social situation that the characters have depending on their work and of their wealth. The most disadvantaged social classes emit an odor that provokes the rejection of the well-off social classes. An odor that cannot be removed by cleaning, but is a symbol of the lower classes. The separation of social classes is manifested through architectural spaces, cinematographic plans and details, where the rich are always at the top, and the poor are at the bottom. Cinema becomes a spokesperson for social and legal aspects, as well as the lack of ethics and shows us a sick and degraded society, to its ultimate consequences.
\end{abstract}

Keywords: Parasite | aporophobia | segregation | human rights

\section{Introducción ${ }^{12}$}

Voz Parásito: "Dicho de un organismo animal o vegetal: Que vive a costa de otro de distinta especie, alimentándose de él y depauperándolo sin llegar a matarlo. Dicho de una persona: Que vive a costa ajena" (Real Academia Española, 2020).

Una de las películas que ha suscitado mayor expectación tanto en la crítica como en el público ha sido $\mathrm{Pa}$ rásitos, de Bong Joon-ho, película surcoreana, y que se alzó con el Óscar en la categoría de mejor película, en 2020 (Merino, 2019; Rocangliolo, 2019; Tomasi, 2019; Orellana, 2020).

El argumento de la película se centra en torno a una familia de gente humilde y pobre, los Kim, que está integrada por el padre, Kim Ki-taek, la madre Chung-sook, el hijo Ki-woo y la hija Ki-jeong. Dicha familia vive en una construcción habitual en la capital de Corea del Sur, Séul, denominada banjiha, que en realidad es un sótano. Este tipo de vivienda resultó ser una solución a los

* frarafer@urb.upv.es 
problemas de espacios habitables que se produjeron en la ciudad derivados de la crisis económica, en las que el acceso a la vivienda por parte de los más pobres era muy difícil, por lo que se legalizaron los búnker o sótanos como espacio habitable (Michel Fariña y Laso, 2019).

A través de su hijo, la familia Kim consigue ocupar puestos de trabajo en la residencia de una familia rica, los Park. Esta familia se integra por el Sr. Park, su esposa, Yeon-kyo, su hija, Da-hye, y su hijo, Da-song. Esta familia dispone de servicio, el ama de llaves Moon-gwang, que está casada con Oh Geun-sae.

El hijo de la familia Kim es el profesor particular de la hija de los ricos; la hija es la mentora del hijo de los ricos; la madre ejerce de criada para todo; y el padre es el chófer. Lo divertido y al mismo tiempo curioso de esta situación, es que la familia rica y empleadora no sabe que ha contratado a una familia completa, y piensa que cada uno procede de un lugar diferente.

Sin embargo, hay un momento en que un miembro de la familia Park, el hijo pequeño, se da cuenta que hay un nexo en común entre todos los nuevos trabajadores: el olor. Cuando comenta esto a su familia, se preguntan si es porque utilizan el mismo detergente para lavar la ropa o gel de baño, y plantean cambiar los productos, para que se puedan diferenciar. Sin embargo, eso no acaba de funcionar, porque el olor que desprende no es sólo un olor físico sino también simbólico. Es un olor que los delata como pobres, aunque todos estén trabajando en el hogar de los ricos y percibiendo un salario. Es un olor que no pueden disimular.

Como indican Michel Fariña y Laso (2019) el olor opera como metonimia del objeto: la vinculación a una familia, los Kim, y el lugar en el que habitan, el sótano. No pueden evitar desprender un olor que está impregnado en sus cuerpos, y que sólo podrían eliminar viviendo en otro lugar, ya que el olor se origina en el sótano, y no se elimina de ninguna forma. Denota su estatus social, de vivir en el subsuelo, y es un olor que resulta rechazable por parte de las clases altas.

Dentro de la filmografía de Joon-ho (Lepastier, 2017; Malausa, 2017; Ruiz, 2017; Tassi, 2017), la presente película refleja de una forma explícita un capitalismo salvaje donde se rechaza a los sujetos por su condición de pobre, a través de un elemento percibido de forma sensitiva como es el olor.

Uno de los núcleos clave de la película implica que los pobres son pobres y habitan en sótanos y espacios cerrados, mientras que los ricos son ricos, habitan en viviendas unifamiliares con espacios abiertos, y en buena medida viven a costa del trabajo de los pobres. Sin embargo, ya que, si bien es cierto que los ricos necesitan a la familia pobre para mantener su nivel de vida, también la familia pobre se ha instalado en la casa de los ricos y depende de ellos para su subsistencia.

El contraste es evidente: los ricos viven en espacios abiertos, en viviendas unifamiliares, con claridad y luz, con aire puro y protección frente a las inclemencias del tiempo. Los pobres viven en espacios cerrados, en sótanos, en medio de la oscuridad, con aire viciado y sin protección frente a las inclemencias del tiempo (Kercher, 2017). De hecho, cuando llueve, su espacio, su casa, se inunda. Se muestra así la dicotomía sobre cómo influye la lluvia en las dos familias. Los Park se encuentran acomodados en su salón, y observan hacia afuera como si hubiera un espectáculo; los Kim, desesperados, huyen hacia el sótano donde habitan, a sabiendas que lo van a encontrar inundado, y eso supone para ellos la desolación. El diluvio se muestra en la película desde arriba hasta abajo, y cuanto más abajo se encuentra el espacio (Michel Fariña y Laso, 2019), mayor es la afectación material que desencadena.

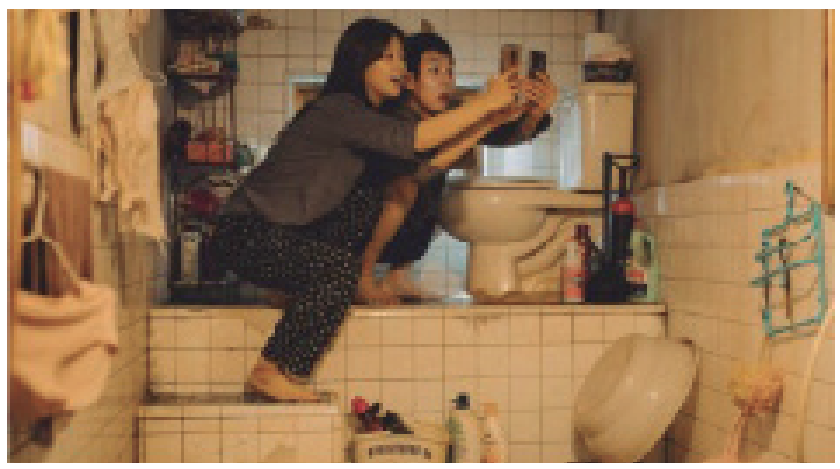

\section{Metodología}

Para realizar este trabajo hemos aplicado las técnicas de análisis narratológico, donde nos centramos en las características de los personajes, como roles que cumplen, y el ambiente donde desarrollan su actividad, que es lo que configura, básicamente, la historia, y cómo se articula con los elementos discursivos. Además, hemos aplicado los conceptos fundamentales del Derecho para entender lo que nos transmite el relato, que es muy importante el desarrollo de relaciones sociales, cómo se ejercen relaciones de dominación entre distintas clases sociales que desembocan en una especie de parasitología social y humana. 


\section{Estructura narrativa}

La estructura narrativa se divide en tres momentos:

\section{Presentación de la familia pobre e instalación en la casa de los ricos}

La presentación de la familia Kim, que es la primera familia pobre, el auténtico motor de los acontecimientos. Esta presentación ya nos sitúa en un mundo donde hay una jerarquización de los seres humanos, es decir, una estratificación social que se manifiesta tanto en el lugar en el que habitan, como en las posibilidades laborales que tienen, lo que condiciona absolutamente sus recursos materiales.

La familia está compuesta por el padre, la madre, el hijo y la hija. Habitan en un sótano, es decir, un lugar ubicado por debajo del nivel del suelo, y sufren las constantes micciones de la gente que pasa por la calle.

Además, el sótano en el que habitan es un espacio cerrado, opresor. Es muy significativo que para poder acceder a un medio de comunicación que les permita ver algo más allá del lugar en que están enclaustrados, la familia Kim roba el wifi a sus vecinos, porque no pueden permitirse el lujo de tener una conexión por internet.

En esta situación desesperada se les presenta una oportunidad: un amigo propone al hijo dar clases particulares a la hija de una familia rica, los Park. Y aquí se inicia un despliegue de recursos tramposos y basados en el engaño por parte de la familia pobre, que van desde la falsificación de un título universitario hasta conseguir expulsar a los otros trabajadores de la familia Park para ocupar su lugar.

La familia rica, los Park, también está constituida por padre, madre, hijo e hija, es la oposición a la familia pobre, son la cara y la cruz de una misma moneda.

Una de las diferencias fundamentales entre la familia rica y las familias pobres es la posibilidad que tiene la familia rica de desarrollar todo tipo de actividades mientras que las familias pobres no tienen esa posibilidad. Es más, en muchos aspectos la familia rica (especialmente la madre) demuestra una ineptitud alarmante para desarrollar las tareas cotidianas, cosa que no ocurre con las familias pobres que realmente son las encargadas de desarrollar las tareas cotidianas que facilitan la vida a la familia rica.

\section{Descubrimiento de que otra familia habita en el subsuelo de la vivienda familiar de los ricos}

Otro de los momentos clave se muestra cuando la familia que se introduce en la casa, los Kim, descubre que en el subsuelo de la vivienda hay otra familia, que está constituida por la antigua criada, que fue sustituida por la nueva criada de forma malévola, y su marido que ocupa el subsuelo de manera permanente. Son la Sra. Moongwang, y el Sr. Geun-sae. Esta situación llega a provocar un conflicto entre las dos familias pobres, por la pugna de su situación dentro de la casa de la familia rica. Como expresan Michel Fariña y Laso (2019), se produce "una lucha despiadada por la supervivencia en la que los desclasados y los empleados pobres se matan mutuamente por ocupar un lugar en la casa de los ricos" (s/d).

Esta situación expone que dentro del estrato social de los pobres y marginados hay distintas categorías y niveles de miseria.

Estos niveles de pobreza en los que hay pobres y más pobres todavía se refleja en el final de la película cuando el pobre que habita el sótano de la familiar Park sale de su habitación, con la finalidad de suprimir su confinamiento, y que motiva todo el desenlace que vamos a explicar a continuación.

\section{El desenlace que es momento en que se produce la masacre, cuando sale del sótano de la casa de los ricos el hombre enclaustrado}

En las escenas finales de la película, cuando se produce el desenlace que lleva a dinamitar la supuesta situación idílica de la familia rica, es donde se observa de forma más clara la diferenciación entre espacio cerrado y espacio abierto.

El confinamiento del personaje que se encuentra en el sótano de la casa de los Park, es el detonante que hace saltar por los aires la estructura contenida hasta este momento en el que se muestra la película.

La estructura muestra de forma muy clara la segregación en los espacios: los ricos siempre se representan dentro de espacios abiertos (de hecho, la familia rica vive en una vivienda unifamiliar con jardín) o espacios luminosos, con luz natural o artificial; mientras que los pobres siempre se muestran en espacios cerrados (la familia pobre vive en el subsuelo de un edificio), con luz artificial, y con claras carencias de habitabilidad. E incluso dentro de los pobres, a los subpobres, podríamos decir, se los representa en un sótano en el que ya no hay ningún tipo de conexión con el exterior. No disponen de ventanas ni de ningún elemento para poder ver la luz del sol.

Precisamente esta dualidad de espacios, abiertos y cerrados, superiores e inferiores (hay que atender también a las escaleras y alturas en la forma de representación de 
las clases sociales), se muestra en el desenlace. El pobre, el Sr. Geun-sae, marido de antigua ama de llaves, que vive en el sótano de la casa de los Park, literalmente "sale" de ese espacio cerrado, a un espacio abierto (el jardín de la casa de los Park) donde se está celebrando una fiesta de cumpleaños del hijo de la familia rica.

Cuando este personaje enclaustrado en el subsuelo sale de su encierro, sufre un deslumbramiento por la luz del sol, dado que se ha mantenido en el sótano alejado de la luz natural. Es un hombre habituado a vivir en la oscuridad. Este personaje también toma protagonismo en el inicio de la película (aunque nos daremos cuenta después) porque es visto por el hijo de los Park, y solamente por él, ya que el resto de la familia no lo ve (Crespo, 2019). El niño lo considera un fantasma, y de hecho lo representa en los dibujos que realiza de una forma distorsionada (Du Mesnildot, 2019a; 2019b).

Después del ataque a Geun-sae, se suceden una serie de acontecimientos que derivan en la muerte de varios personajes. Aquí entra en juego también la gestualidad de uno de los personajes, que además provoca el ataque del padre de la familia pobre. Nos estamos refiriendo a que el personaje que encarna al padre de la familia rica, quien se tapa la nariz porque no puede soportar el olor de los pobres. Este momento refleja con toda su contundencia el rechazo, la aporofobia, entendida como el rechazo al pobre, ya que con un gesto lo está rechazando, sin mediar palabras.

\section{Segregación, aporofobia, plutofilia y derechos fundamentales}

La segregación como concepto consiste en separar al sujeto diferente del resto, de considerarlo como de segunda categoría o de categoría inferior, o como indica la Real Academia Española (2020) "separar y marginar a una persona o a un grupo de personas por motivos sociales, políticos o culturales", se muestra en Parásitos en todos los espacios de la casa.

En el caso de Parásitos el propio título da lugar a una dualidad de interpretación: no hay solamente un tipo de parásito. En última instancia, los distintos grupos de personajes (familia Park, familia Kim y familia Sr. Geun-sae y Sra. Moon-gwang) se parasitan entre ellos de forma constante. Durante el visionado de la película, la perspectiva subjetiva del parasitismo va cambiando de opinión en el espectador, y queda más claro cuando todavía hay parásitos de los parásitos de los parásitos. El caso extremo es el personaje masculino que habita en el sótano, y que únicamente puede parasitar a otros personajes para subsistir.

Se produce también una mutación de los personajes: la familia Kim, que presenta al inicio de la película un aspecto desaliñado y poco cuidado, cuando entran al servicio de la familia Park cambian de aspecto e incluso es difícil de reconocerlos, ya que presentan una presencia más cuidada, así como un comportamiento y unos modales más refinados (Kovacsics, 2019).

En ese ámbito jurídico podemos invocar varios preceptos de la Constitución Española que se observan no se cumplen en la representación y en el argumento de la película. En este sentido, la familia pobre está desprotegida en el ámbito social y económico (artículo 39 de la Constitución Española), y también se muestra la discriminación en los sujetos (artículo 14 de la Constitución Española) o el libre desarrollo de la personalidad (artículo 10 de la Constitución Española).

La violación de Derechos Humanos a través de la marginación que sufren los personajes de las familias pobres, unos más que otros, ya que el personaje que habita en el sótano de la familia rica es un claro ejemplo de marginación absoluta en todos los sentidos, ya que no dispone de recursos ni de un espacio para poder vivir de forma digna. Podemos destacar la violación de los siguientes derechos, teniendo en cuenta la Declaración Universal de los Derechos Humanos, adoptada y proclamada en la Resolución 217 A(III), en París, en 1948:

1. Derecho a su seguridad (artículo 3);

2. Sometimiento a trato cruel, inhumano o degradante (artículo 5);

3. Derecho al trabajo y a la protección del desempleo (artículo 23);

4. Derecho a un nivel de vida adecuado para asegurar al sujeto y a su familia un estado de salud y bienestar, respecto a la alimentación, vestido, vivienda, asistencia médica y servicios sociales, así como el derecho a los seguros en caso de desempleo, enfermedad o invalidez, y en otros casos de pérdida de los medios de subsistencia por circunstancias ajenas a su voluntad (artículo 25);

5. Derecho al establecimiento de un orden social e internacional en el que los derechos y libertades sean plenamente efecticos, tal y como aparecen en la Declaración (artículo 28). 
Respecto a la aporofobia, el rechazo al pobre, en la película tiene numerosas connotaciones, pero se refleja de forma muy clara en los gestos que realizan los personajes (durante los trayectos en el coche, en la estancia en la casa, y antes del desenlace final en el jardín), de taparse la nariz para evitar olerlos. El olor a pobre provoca el rechazo de los ricos. Un olor que no es percibido por el propio pobre, pero que le denota su clase social inferior. Es un olor derivado de la ubicación de la vivienda, un subsuelo en el que no hay ventilación, y que por las humedades y condiciones infrahumanas en las que viven, se penetra en la piel y la ropa, a modo de distintivo invisible de su origen social inferior, y que provoca una segregación de los personajes.

Este concepto, la aporofobia, es una forma de discriminación. El término acuñado por Cortina (2017) se refiere a comportamientos y actitudes en forma de rechazo a la persona pobre (Picado et al., 2019). En ocasiones utilizamos patrones como juicios de valor sobre la imagen de un sujeto en relación con su situación personal, económica y dentro de la sociedad. No se identifica con el rechazo a una etnia, ni raza, ya que dentro de las mismas se produce la aporofobia. Es el rechazo a la persona pobre, sea cual sea su raza, etnia o nacionalidad (Carrascosa, 2018; Roca, 2019).

Se relaciona también con la idea de incomodidad o de no pertenencia al mismo grupo o pertenencia social ( $\mathrm{Pi}$ cado et al., 2019). Y ello se observa en la película, ya que el hijo de la familia Park, el que en un primer momento identifica a los pobres por el olor, se siente incómodo por dicha circunstancia. Le incomoda que en su casa haya sujetos que huelan de forma diferente al resto del grupo, el grupo de los ricos. Inmediatamente los identifica como de otro grupo o pertenencia social diferente al resto.

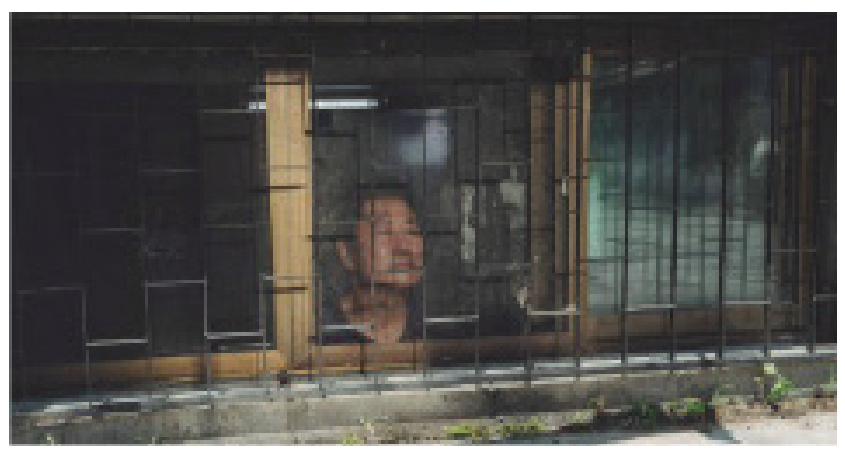

Como advierten Michel Fariña y Laso (2019) la familia Kim no percibe su olor y, además, no son capaces de disimularlo o enmascararlo de alguna forma. Huelen diferente y ello es percibido por la familia Park en dife- rentes ocasiones que se muestran en la película. Pueden aparentar los Kim competencias profesionales que no poseen, e incluso disimular que son familia, pero no les resulta posible disimular su origen y ello es por culpa de cómo huelen para los ricos.

La aporofobia se sustenta en la discriminación a los pobres por el simple hecho de serlo, ya sea por miedo o aversión. Una parte de la población desprecia a otra por su condición económica, y los considera inferior, por lo tanto se crea hostilidad hacia estas personas de escasos recursos económicos. La consecuencia fundamental de la aporofobia, además del rechazo a las personas más vulnerables, restringir su acceso a determinados derechos sociales como la sanidad o la educación.

Se produce una violación de los derechos mencionados anteriormente a las personas pobres (Gimeno, 2000). Así, por ejemplo, podemos destacar que la aporofobia implica un comportamiento de discriminación, como hemos indicado anteriormente, y nos referimos a un comportamiento intolerante con los sujetos (Picazo et al., 2019). El artículo 2 de la Declaración Universal de los Derechos Humanos indica lo siguiente:

Toda persona tiene todos los derechos y libertades proclamados en esta Declaración, sin distinción alguna de raza, color, sexo, idioma, religión, opinión política o de cualquier otra índole, origen nacional o social, posición económica, nacimiento o cualquier otra condición. Además, no se hará distinción alguna fundada en la condición política, jurídica o internacional del país o territorio cuya jurisdicción dependa una persona, tanto si se trata de un país independiente, como de un territorio bajo administración fiduciaria, no autónomo o sometido a cualquier otra limitación de soberanía.

Se produce, por tanto, la exclusión de los sujetos, y con ello una violación o limitación de sus derechos como personas (Bellveser, 2018).

La pobreza y su invisibilidad por cuanto los pobres son una molestia para una sociedad diseñada para el éxito, se manifiesta también en la película. Los problemas de los pobres no interesan a las clases ricas. Se convierten en seres invisibles (Sebastián, 2018), no pueden manifestar sus problemas, y no pueden esperar una solución a los mismos por parte de las clases más favorecidas.

La pobreza se convierte en una situación social, y precisamente el pobre es el que necesita de las ayudas estatales para poder avanzar, y que, sin embargo, no siempre obtiene, ya que la estructura política y económica no lo permite, por determinadas circunstancias, y se produce la exclusión de los excluidos. 
La aporofobia es una cuestión no sólo de concienciación social, sino de solidaridad (Rodríguez, 2018) hacia los sujetos, de comportamiento ético (González, 2019), ya que no se dirige a unos sujetos concretos, sino en abstracto, por su condición, independientemente de los elementos subjetivos (Ortega, 2019). Enlazaría también con lo que se ha denominado ceguera moral como "incapacidad para identificar la condición de vulnerabilidad de los demás” (Ayala, 2018).

La Constitución Española, en su artículo 1, indica que: "España se constituye en un Estado social y democrático de Derecho, que propugna como valores superiores de su ordenamiento jurídico la libertad, la justicia, la igualdad y el pluralismo político".

La aporofobia en un estado democrático es una forma máxima de desigualdad, por lo que no respeta los valores del ordenamiento jurídico, además de que el artículo 14 de la Constitución Española preceptúa el principio de igualdad, indicando que "Los españoles son iguales ante la ley, sin que pueda prevalecer discriminación alguna por razón de nacimiento, raza, sexo, religión, opinión o cualquier otra condición o circunstancia personal o social".

Vemos, pues, que si atendemos tanto a la legislación internacional como en la nacional española, no se permite la aporofobia, tanto según lo indicado en la Declaración Universal de Derechos Humanos, como en la Carta Magna (García, 2019).

\section{La involución de la comunicación como consecuencia de la falta de recursos económicos}

Otro de los aspectos que queda reflejado en Parásitos es la involución en el ámbito de las comunicaciones. Se pasa desde las primeras imágenes de la película de la conexión vía wifí, a finalizar la misma a través de la comunicación mediante código morse.

Aquí se refleja otro de los aspectos de las clases sociales: los ricos gozan de los medios más avanzados de comunicación, y los pobres ven limitado el acceso a los nuevos medios de comunicación: unos porque tienen que pagar el acceso a internet, y otros porque desde su posición les resulta absolutamente acceder a nada. Se ha quedado estancado en esa época, sabía el código morse. Resalta el desconocimiento de este medio de comunicación por parte de las clases altas, excepto el niño que lo conoce por asistir a campamentos.

\section{Capitalismo, envidia y clases sociales}

Otro aspecto a destacar es el reflejo del capitalismo que se muestra en la película Parásitos. Si contemplamos la vida que lleva la familia Park y la familia Kim observaremos numerosas diferencias en relación con las clases sociales.

Los lujos de la familia Park son convertidos en necesidades, ya que la familia rica dispone de numerosos elementos superficiales que los considera indispensables para la vida diaria. Sin embargo, la familia pobre, y la familia subpobre carece de los elementos mínimos para poder llevar una existencia digna. Sus necesidades no son lujos, y precisamente carece de todos ellos. No dispone ni de una vivienda adecuada, ya que en caso de cualquier inclemencia meteorológica no puede subsistir, por no decir la situación del pobre que habita en el sótano de los ricos, que no dispone ni siquiera de una ventana, ni de ningún medio para poderse comunicar, salvo el código morse.

Se observa, pues, la degradación sucesiva de las clases sociales, hasta las condiciones infrahumanas de existencialidad de los más pobres.

Se pone de manifiesto en la película que los recursos no son accesibles para todas las clases sociales: lo que se ha denominado "democratización del lujo", por ejemplo, en el caso de los electrodomésticos de uso doméstico. En las familias de los pobres, no se contempla que dispongan de los mismos; mientras que los ricos disponen de una vivienda domotizada.

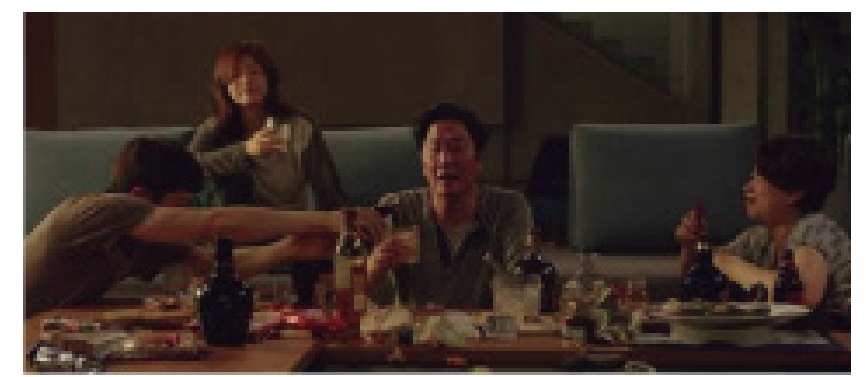

Otro elemento a considerar es la envidia que se percibe en las clases sociales que se muestra en la película. Los pobres envidian a los ricos, de hecho, intentan acceder a su "ecosistema" mediante el desempeño de puestos de trabajo para poder disfrutar de comodidades reservadas sólo a los ricos. Pero esa envidia encubre en ciertas escenas un deseo de eliminación de los ricos, con la intención de que el pobre ocupe su lugar. Ello resulta muy palpable cuando los pobres, después de irse los ricos a pasar unos días fuera, se quedan en la casa, y se empieza a comportar como si fueran los habitantes de la misma. 
La plutofilia se observa principalmente en las clases pobres, que desean disponer de los recursos de los ricos, de anhelar las riquezas del otro (Maas, 2019). El deseo de riqueza resulta particularmente interesante ya que su contraposición, el deseo de pobreza, no se produce en ningún caso (Terradillos, 2020). Los ricos nunca anhelan vivir como los pobres, con lo que ese deseo es una manifestación del reparto aleatorio de los recursos tanto económicos como sociales, que no siguen una disciplina exacta para su alcance. Consideramos que la contraposición aporofobia y plutofilia son la distinta cara de un mismo concepto asociado a los recursos, la aporofobia como el rechazo a quien no dispone de recursos; y la plutofilia como el anhelo de disponer de los recursos que tienen los ricos. Hay que indicar que la plutofilia es unidireccional, ya que es el pobre el que desea los recursos; sin embargo, la aporofobia puede ser contemplada no sólo por parte de los ricos, sino también por parte de los pobres, según el grado de pobreza.

Recordemos a Adam Smith, que ya en el siglo XVIII, manifiesta: "La disposición a admirar y casi idolatrar a los ricos y poderosos y despreciar a las personas de condición pobre y humilde es la más grande y universal causa de corrupción de nuestros sentimientos morales" (En Araya et al., 2018). Especialmente contemplamos ese deseo de riqueza en Parásitos de diversas formas: en la significativa escena de la finalización de la película, como una ensoñación, en el que el hijo mayor de la familia Kim se visualiza en un futuro como dueño de la casa de los Park, y el reencuentro con su padre que ocupa el lugar del subparásito, después de la matanza que se produce en la fiesta de cumpleaños. Pero no solamente en esa escena, que consideramos especialmente significativa, sino también en otros momentos de la película, como por ejemplo cuando la familia Park se marcha al campo, y la familia Kim se queda en la casa ocupándola como si fuera suya. De hecho, ahí, en ese momento, se produce también el momento sublime en el que la anterior sirvienta se introduce en la casa, tras el acceso que le facilita la familia Kim, y se descubre la existencia del marido que vive en el sótano. Es precisamente ahí donde contemplamos la aporofobia por parte de los menos pobres hacia los más pobres dentro del concepto de pobreza, ya que la familia Kim rechaza a la familia compuesta por el Sr. Geun-sae y la Sra. Moon-gwang, precisamente porque son más pobres que ellos, y consideran que anhelan su posición dentro de la casa, ya que disponen todos ellos de trabajo. Ahí, se observa de forma muy clara la existencia de los dos conceptos relacionados en las familias protagonistas: la familia Kim anhela la riqueza de la familia Park, y la familia del Sr. Geu-sae y la Sra. Moon-gwang desea la "riqueza" de la familia Kim. La familia Park rechaza la pobreza, se observa la aporofobia de forma muy clara, de la familia Kim, y a su vez, la familia Kim rechaza la pobreza del Sr. Geu-sae y la Sra. Moon-gwang.

\section{Conclusiones}

La película Parásitos se estructura en buena medida a partir de oposiciones: ricos-pobres, espacios abiertos-espacios cerrados, arriba-abajo, etc. (Ramírez, 2019). Podemos desarrollar las siguientes conclusiones:

1. Hay un doble concepto de parásitos. Por una parte, los parásitos manifiestos, que serían las dos familias pobres que se encastran en la casa del rico para poder vivir, especialmente en el caso del hombre que lleva años viviendo en el subsuelo de la vivienda unifamiliar, como si fuera un virus latente, que permanece escondido, hasta que, finalmente, acaba saliendo. Conviene recordar que el padre de la primera familia pobre, al final del relato, hace exactamente lo mismo, y volverá a vivir en el ese submundo, sin dejarse ver.

2. Los personajes pobres toman esporádicamente las propiedades de los ricos, para poder subsistir. Sin embargo, también los ricos son parásitos, en tanto que dependen, en buena medida, del trabajo de los pobres para poder subsistir. Más que simbiosis, podemos decir que hay un parasitismo porque las relaciones que se ejercen son de dominio inclusive y de imposición, no se muestra ninguna normativa de defensa del trabajador, ni ningún estatuto para regular la situación, además de no aparecer en la película ninguna referencia a un contrato de trabajo.

3. El lugar donde habitan los personajes tiene un carácter claramente simbólico. Los pobres viven en espacios cerrados y opresivos, inclusive en algún caso ni siquiera ven la luz del día. Los ricos viven en espacios abiertos, iluminados y con jardín, reflejo de su calidad de vida.

4. Hay un claro descenso simbólico a los infiernos por parte de los pobres. Si los ricos viven arriba, los pobres deben vivir abajo, en los sótanos, en 
un infierno simbólico y al mismo tiempo real, ya que no les queda otro modo de vida.

5. Se aprecia en la película una picaresca, podríamos decir a similitud de la literatura del Siglo de Oro español, como en el Lazarillo de Tormes, con la figura del pícaro, que se inventa uno y mil recursos para sobrevivir en una sociedad adversa (Yáñez, 2019a; 2019b). De hecho, a raíz de la capacidad de inventar estrategias, la familia pobre se instala en la familia rica, después de conseguir que despidan a varios de sus antiguos sirvientes.

6. Desde el punto de vista jurídico, la película nos aporta muchos argumentos para posicionarnos en la lucha de clases, y en el concepto de rechazo al pobre, la aporofobia aparece en todas y cada una de las escenas del filme, de forma liminal y subliminal.

7 En la sociedad que muestra la película, no tiene cabida el sujeto que carece de medios, el que no ha podido obtener recursos se queda fuera del sistema, y es el que va a sufrir las consecuencias, incluso climatológicas, por no disponer de una vivienda adecuada que la permita sobrevivir. Se trata de la negación de los derechos más elementales, y en el que se pone en tela de juicio el Estado del bienestar.

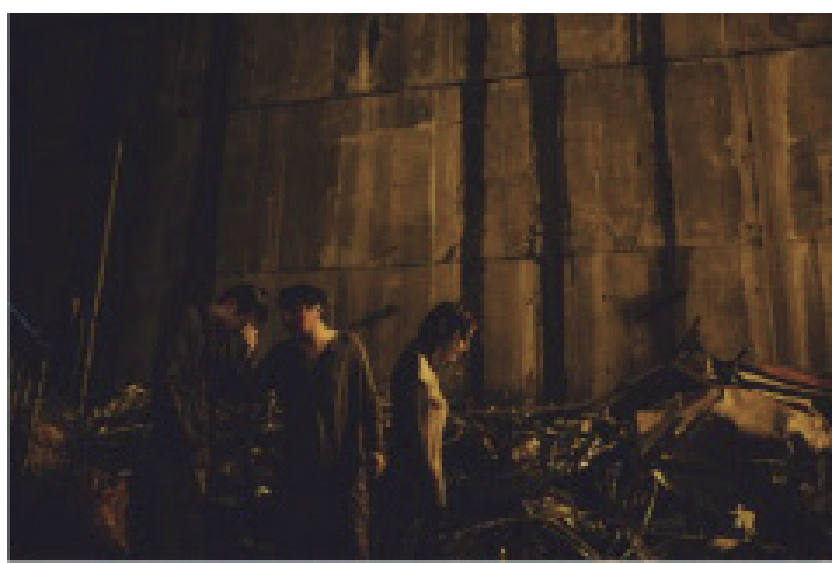

\section{Referencias}

Araya Pizarro, S., Varas Madrid, C., y Poblete Ibaceta, M. (2018). Ética y emprendimiento: una reflexión sobre los valores del emprendedor del siglo XXI. Revista Dos Puntas, (17), 175-194. https://dialnet.unirioja.es/servlet/articulo?codigo=7440770

Ayala Enríquez, P. (2018). La simpatía smithiana como vía para reducir la aporofobia derivada de la corrupción. Veritas: revista de filosofía y teología, (41), 69-86. https://scielo.conicyt.cl/scielo.php?script=sci_arttext\&pid=S0718-92732018000300069\&lng=es\&n$\mathrm{rm}=\mathrm{iso} \& \mathrm{t} \operatorname{lng}=\mathrm{es}$

Bellveser, R. (2018). Derechos humanos y aporofobia. Movimiento escritores pro derechos humanos, (2), 595-601.

Bong, J. (director). (2019). Parásitos [película]. Barunson E\&A; CJ Entertainment

Carrascosa Bermejo, M. D. (2018). Libre circulación de ciudadanos comunitarios inactivos y protección social: ¿̇sufre la UE de aporofobia?. En J.M. Miranda Boto (dir.) El Derecho del Trabajo español ante el Tribunal de Justicia: problemas y soluciones, (pp. 505-533). Cinca.

Cortina Orts, A. (2017). Aporofobia, el rechazo al pobre: un desafío para la democracia. Paidós.

Crespo, I. (2019). «Parásitos», Células durmientes. Cinemanía, (289), 74-77.

Du Mesnildot, S. (2019a). Parasite de Bong Joon-ho: Dans la prison de verre. Cabiers du cinema, (755), 20-22.

Du Mesnildot, S. (2019b). Fantômes de la société coréenne: entretien avec Bong Joon-ho”. Cabiers du cinema, (756), 38-40.

García Domínguez, I. (2019). Aporofobia: una investigación cualitativa al colectivo de personas sin hogar en Salamanca. Ars Iuris Salmanticensis: AIS: revista europea e iberoamericana de pensamiento y análisis de derecho, ciencia politica y criminología, 7(2), 2553. https://dialnet.unirioja.es/servlet/articulo? codigo $=7273488$

Gimeno Perelló, J. (2000). Derechos Humanos: Racismo y aporofobia. El Viejo topo, (141), 7-8.

González Avión, S. (2019). Aporofobia: un desafío para la democracia. Encrucillada: Revista galega de pensamento Cristián, 43(211), $60-70$.

Kercher, D. M. (2017). Los espacios fangosos del cine negro globalizado: desde Hitchcock y Bong Joon-Ho a La isla mínima. En J. Sánchez Zapatero y A. Martín Escribà (coord.), La globalización del crimen: literatura, cine y nuevos medios (pp. 523-530). Andavira.

Kovacsics, V. (2019). Mutaciones: Bong Joon Ho. Memories of murder. Caiman cuadernos de cine, (86), 82.

Lepastier, J. (2017). Okja de Bong Joon-ho: Monstre domestiqué. Cabiers du Cinema, (734), 28-29.

Maas, A. (2019). Aporofobia y plutofilia. Revista de la Universidad de México, (7), 68-76. https://www.revistadelauniversidad.mx/ articles/ba725cbc-9db5-434a-87b2-959e045d2507/aporofobia-y-plutofilia 
Malausa, V. (2017). L’ami Okia: entretien avec Bong Joon-ho. Cabiers du cinema, (729), 10-12.

Merino, I. (2019). Cinema: Zombis, feminisme, drames reals, lluita de clases i marades bavoses a Canes. L'Avenc: Revista de historia i cultura, (459), 68-72.

Michel Fariña, J.J., y Laso, E. (2019). La otredad y la náusea. Ética y cine. http://eticaycine.org/Parasite

Orellana Gutiérrez de Terán, J. (2020). Unos Óscar que dan que pensar. Crítica, (1051), 34-39.

Ortega Esquembre, C. (2019). La aporofobia como desafío antropológico. De la lógica de la cooperación a la lógica del reconocimiento. Daimon: Revista de filosofía, (77), 215-224. https://revistas.um.es/daimon/article/view/319071/261421

Picado Valverde, E. M., Nieto Librero, A.B., Guzman Ordaz, R., Yurrebaso A., y Jáñez González, A. (2019). Detección de la discriminación hacia los pobres, «aporofobia». Miscelánea Comillas: Revista de Ciencias Humanas y Sociales, 77(151), 417-430. https:// revistas.comillas.edu/index.php/miscelaneacomillas/article/view/12228/11360

Ramírez Herrera, M.C. (2019). La interrelación entre espacio y locura en las novelas contemporáneas materialistas de Benito Pérez Galdós. Universidad de Málaga. https://www.educacion.gob.es/teseo/imprimirFicheroTesis.do?idFichero=\%2Fpzr\%2BAqzEZ$\mathrm{Q} \% 3 \mathrm{D}$

Roca Oliver, E.A. (2019). Aporofobia versus negrofobia: identidad y política en África poscolonial. En E. González Esteban, J.C. Siurana, J.L. López González, y M. García-Granero Gascó (coord.) Ética y democracia: desde la razón cordial. (pp. 405-411). Comares.

Rocangliolo, S. (2019). Gente pobre. Fotogramas \& DVD: La primera revista de cine, (2014), 10.

Rodríguez Aramayo, R. (2018). Solidaridad. Eunomía: Revista en Cultura de la Legalidad, (15), 169-175. https://e-revistas.uc3m.es/ index.php/EUNOM/article/view/4346/2891

Ruiz, J. (2017). Alma de fabulador: Okja, Bong Joon-ho. Caimán cuadernos de cine, (61), 67.

Sebastián Solanes, R. F. (2018). La aportación de Juan Luis Vives al estudio de la pobreza. Del socorro de los pobres a la aporofobia. Vivesiana: revista de l'Associació d'Amics de Lluís Vives de la Universitat de València, (3), 75-88. https://ojs.uv.es/index.php/ vivesiana/article/view/11428/10889

Tassi, F. (2017). Okja: di Bong Joon Ho. Cineforum, (566), 76.

Terradillos Basoco (2020). Política criminal de exclusión: aporofobia y plutofilia. Revista penal, (46), 230-244.

Tomasi, D. (2019). Parasite: di Bong Joon-Ho. Cineforum, (590), 17-19.

Real Academia Española. (2020). Voz Aporofobia. https://dle.rae.es/aporofobia

Real Academia Española. (2020). Voz Parásito. https://dle.rae.es/?w=par\% C3\%A1sito

Real Academia Española. (2020). Voz Segregar. https://dle.rae.es/segregar?m=form

Yáñez Murillo, M. (2019a). El cine fantástico conquista Cannes. Fotogramas E DVD: La primera revista de cine, (2109), 54-55.

Yáñez Murillo, M. (2019b). Lucha de clases y picaresca a la coreana. Fotogramas E DVD: La primera revista de cine, (2112), 98-99.

1 Trabajo realizado en el marco del Proyecto I+D+i «Retos investigación» del Programa estatal de $\mathrm{I}+\mathrm{D}+\mathrm{i}$ orientado a los Retos de la Sociedad del Ministerio de Ciencia, Innovación y Universidades: RTI2018-097354-B-100 (2019-2022) y Proyecto de I+D+i Retos MICINN (PID2019-108710RB-I00, 2020-2022).

2 Los autores han contribuido en la misma medida en la elaboración del presente trabajo. El orden de firma ha sido determinado exclusivamente siguiendo el criterio alfabético del segundo apellido de cada autor. 